Available online on 15.11.2016 at http://jddtonline.info
(c) 2016, publisher and licensee JDDT, This is an Open Access article which permits unrestricted
noncommercial use, provided the original work is properly cited

Review Article

\title{
MANAGEMENT OF GLAUCOMA: EFFECTIVE DRUG DELIVERY VIA NIOSOMES
}

\author{
Chauhan Meenakshi K.*, Yenamandra Jahnavi
}

Department of Pharmaceutics, Delhi Institute of Pharmaceutical Sciences and Research, Pushp Vihar, Sec-3, New Delhi, India-110017

\begin{abstract}
Glaucoma is a term used for a group of diseases; associated with optic nerve damage which leads to loss of retinal ganglionic cells. The changes stimulated in the optic nerve head cause visual field restriction which may ultimately result in blindness. Conventionally, the drugs used in treatment are ocular anti-hypertensives and are available as eye drops. Challenges faced in ocular delivery of a drug reduce the efficacy of such formulations. In a disease like glaucoma which is a leading cause of irreversible blindness, effective delivery of drug to the site of absorption is paramount in order to prevent disease progression. The novel drug delivery systems have shown great promise in this regard. They have been developed with a viewpoint to improve ocular retention of therapeutic agents. Niosomes have been exploited well and have elicited a positive response. The review is aimed at bringing out facts about the disease including worldwide prevalence, types, treatment, its impact and also constraints in ocular drug delivery, drug delivery alternatives, and niosomes in particular with their composition, advantages and their potential in management of ocular hypertension.
\end{abstract}

Keywords: Glaucoma, ocular drug delivery, niosomes, IOP, novel drug delivery.

*Corresponding author

Meenakshi K. Chauhan, NDDS Research Laboratory, Department of Pharmaceutics, Delhi Institute of Pharmaceutical Sciences and Research, Govt. of NCT of Delhi, Pushp Vihar, Sec-3, New Delhi, India-110017, Email: meenakshindds @ gmail.com

Article Info

Received 27 July 2016; Review Completed 05 Sep 2016; Accepted 04 Nov 2016, Available online 15 Nov 2016

URI: http://jddtonline.info/index.php/jddt/article/view/1313

Cite this article as: Chauhan Meenakshi K., Yenamandra Jahnavi, Management of glaucoma: effective drug delivery via Niosomes, Journal of Drug Delivery \& Therapeutics. 2016; 6(6):48-53 DOI: http://dx.doi.org/10.22270/iddt.v6i6.1313

\section{INTRODUCTION}

Glaucoma is characterized by optic neuropathy, cupping and atrophy of optic disk, loss of peripheral vision and reduction in visual acuity at advanced stages. It has been heralded as one of the major causes of blindness around the world $^{1,2}$. Global awareness regarding the disease is poor thus disease goes unnoticed usually until advanced stage has set in. The diagnosis and criteria set to discern the onset of disease has been variable thus complicating the scenario. The primary mode of management is maintaining the elevated (IOP) intraocular pressure at a permissible level where further damage of the nerves is prevented. For this, medications are prescribed that are instilled topically. The shortcoming of such treatment lies in the fact that conventional eye drops are unable to deliver a substantial amount of drug to the ocular tissue leading to reduced efficacy ${ }^{3,4}$. Newer delivery systems have been evaluated; of which niosomes offer many advantages such as, being able to deliver the drug for a prolonged period of time, increased stability against degradation and scope for surface modification which leads to enhanced efficacy, better penetration etc., ${ }^{4,5}$.

\section{WORLDWIDE PREVALENCE}

According to the reports published in literature as of now close to $3.54 \%$ people over the age of 40 suffer from glaucoma around the globe and it presents as the leading cause of irreversible loss of sight ${ }^{6}$. Figures of close to 80 million people being affected by the disease by the year 2020, which is expected to rise to 111 million by end of 2040 have been reported ${ }^{6,7,8}$.

Indian Scenario: It is estimated that in India alone the number of people with glaucoma is set to rise to 16 
million by the end of 2020 as compared to 11.9 million as affected by both types of glaucoma by $2010^{8}$. The prevalence of any type of glaucoma in India was found to be $2.6 \%$ of which, (POAG) primary open angle glaucoma contributed $1.6 \%$ and (PACG) primary angle closure glaucoma $0.5 \%^{9-11}$. As the rise in cases of glaucoma is substantial, increased awareness of disease and better therapeutic options must be made available.

\section{TYPES OF GLAUCOMA}

Though many variants of the disease exist, the most common form is (OAG) open angle glaucoma followed by (ACG) angle closure glaucoma ${ }^{1}$. Other forms include secondary glaucoma, congenital glaucoma, etc. ${ }^{12}$. These forms may have either sudden onset or may preside over a long period of time and by any which way the damage caused to the nervous tissue of the eye is severe and leads to visual impairment.

Treatment: Presently the treatment regimen constitutes use of medicinal agents to reduce the elevated IOP which also helps in delaying progression of the disease. Surgical procedures are resorted to when patient is unresponsive to medicinal agents ${ }^{13}$. Different classes of drugs available to manage IOP are listed below ${ }^{14}$ :

i. $\quad \beta$-Blockers: The agents used are Timolol maleate, Betaxolol, Levobunolol, etc., these are plagued with cardiopulmonary side effects and central nervous system side effects. ii. Miotics: The agents used are Pilocarpine, Carbachol, etc., these present side effects related to blurred vision, near sightedness, reduced pupil size that affects night vision and parasympathomimetic side effects.

iii. Sympathomimetics: The agents used are Dipivefrin, Epinephrine, etc., these present side effects in form of allergic symptoms and elevated blood pressure.

iv. $\quad \alpha_{2}$-Adrenergic Receptor Agonists: The agents used are Brimonidine tartrate and Apraclonidine, these present side effects that include allergic reactions such as blepharoconjunctivitis and elevated blood pressure etc.

v. Carbonic Anhydrase Inhibitors: The agents used are Acetazolamide, Dorzolamide, etc., side effects associated with oral therapy are high which include frequent urination, aplastic anemia etc.

vi. Prostaglandin Analogs: Their examples include Latanoprost, Bimatoprost, etc. These present side effects such as ocular irritation and upper respiratory tract symptoms.

\section{TRENDS ASSOCIATED WITH DISEASE}

A lot of studies have been conducted and the results have been used to estimate the pattern of the disease and the populations most affected by it. Some of the data related to glaucoma has been tabulated (Table 1). Risk factors and their attributes implicated in development of glaucoma have also been presented (Table 2).

Table 1: Trends Observed with Disease

\begin{tabular}{|l|l|l|}
\hline Factors & POAG & PACG \\
\hline Global prevalence & $3.05 \%$ & $0.5 \%$ \\
\hline Ethnicity & African descent & Asian descent \\
\hline Age & Above 40 years & Above 40 years \\
\hline Gender & Male predisposition & Female predisposition \\
\hline Ocular condition & Myopia, Ocular Hypertension & Corneal thinning \\
\hline Diagnosis & Tonometry & Gonoscopy \\
\hline
\end{tabular}

Ethnicity: As far as the trends are concerned, people with African ethnicity are more likely to develop open angle glaucoma ${ }^{6-8,15-17}$ whereas Asians are known to be greatly affected by PACG than white populations ${ }^{12,18}$. China might be the leader in most cases with angle closure glaucoma $47.5 \%$ in total of all cases reported ${ }^{8}$.

Age and Metabolic disorders: The increase in number of glaucoma cases worldwide especially in developing countries has also been attributed to the fact that a large segment of its population is aging. Those above the age of 70 have increased risk of the disease due to alteration in health owing to development of metabolic diseases simultaneously. In an analysis it was found that effect of age, varied with the geographical region and in people with European descent there was a steeper rise in glaucoma cases with a decade increase in age ${ }^{8,19}$.

Table 2: Risk Factors Implicated in Disease Development:

\begin{tabular}{|l|l|}
\hline Risk factors & Attributes \\
\hline Elevated Intraocular pressure $^{7,13,20}$ & Greater than $25 \mathrm{~mm} \mathrm{Hg}$ \\
\hline Cup-to-disk ratio $^{15,20}$ & Greater than 0.3 \\
\hline Age $^{6-8}$ & Over 40, higher incidence of those over 70 \\
\hline Familial history of glaucoma $^{7,13,16}$ & Genetic predisposition \\
\hline Heritage $^{6-8,16-18}$ & African; Asians; Hispanic \\
\hline Ocular diseases $^{7,13}$ & Eye trauma, thinning in central cornea, myopia or hyperopia \\
\hline Metabolic diseases $^{7,13}$ & $\begin{array}{l}\text { Those suffering from diabetes, migraines, high blood pressure, poor circulation } \\
\text { or other health problems }\end{array}$ \\
\hline
\end{tabular}




\section{IMPACT OF GLAUCOMA}

It can be broadly divided into two parts where we can attribute it to quality of life associated with the disease and economic burden of the disease.

\section{- Quality of life:}

In a study published by WHO it was estimated that close to 5.2 million people would be blind due to glaucoma until 1990 accounting for $15 \%$ of total global blindness ${ }^{20}$. Given the steep rise in glaucoma cases worldwide and with aging population, it was later postulated that by 20108.4 million would be bilaterally blind of which POAG contributes to 4.5 million cases ${ }^{8}$, 21. PACG though not widely reported has been responsible for about $50 \%$ of blindness caused by glaucoma $^{12}$. Blindness not only impairs the person but also influences quality of life of that person. A lot of care needs to be given to such patients when loss of sight occurs. As people are unable to work on their own, it affects their mental well being; self esteem and might lead to depression ${ }^{21}$.

\section{- Economic burden:}

The costs incurred during treatment of glaucoma not only include the direct medical costs (i.e. those associated with medicines, physician fees etc.) but also indirect costs. The indirect costs can be identified as loss of days in work, lower productivity due to vision impairment and nursing charges, etc., ${ }^{21-22}$. In a study conducted across Europe, it was found that costs incurred increased linearly with disease severity ${ }^{19}$. Also a patient may have to visit the physician 10 million or more times for follow up ${ }^{22}$, such high number of visits not only demands a lot of time, money and physical effort but also lead to increased economic burden of disease.

\section{CONSTRAINTS IN OCULAR DRUG DELIVERY}

Eye is protected by a barrage of mechanisms and a large amount of drug is lost with topical instillation due to reasons such as; poor corneal penetration, loss of drug via conjunctival absorption, nasolacrimal drainage, precorneal metabolism, reflex blinking, tear dilution, etc. Rapid removal of drug from the site of absorption leads to less than $2 \%$ of the amount of drug that is administered being absorbed leading to decreased ocular bioavailability of a drug ${ }^{1,3}$. Other conventional dosage forms such as ointments and suspensions though available are not favored as much due to eye irritation and blurring of vision associated with them.

\section{DRUG DELIVERY ALTERNATIVES FOR OCULAR DELIVERY}

A leap in the science of novel drug delivery systems has led to invent of various types of drug delivery systems. The novel systems used in ocular drug delivery have proven to be advantageous in overcoming the ocular barriers and attend to problems associated with patient compliance and low ocular bioavailability of medicinal agents. Various drug delivery systems have been presented at a glance (Table 3).

Table 3: Aspects of Novel Drug Delivery Systems

\begin{tabular}{|l|l|l|}
\hline $\begin{array}{l}\text { Novel Drug } \\
\text { Delivery System }\end{array}$ & Composition & Advantages \\
\hline Ocular inserts ${ }^{23,26}$ & $\begin{array}{l}\text { Made up of soluble/insoluble polymers. } \\
\text { Drug is either dispersed in polymer matrix or } \\
\text { soaked into the insert }\end{array}$ & $\begin{array}{l}\text { Increased residence time of formulation } \\
\text { No frequent dosing of drug } \\
\text { Accuracy of drug }\end{array}$ \\
\hline $\begin{array}{l}\text { In-situ gelling } \\
\text { systems }\end{array}$ & $\begin{array}{l}\text { The formulation is incorporated with gelling } \\
\text { agents } \\
\text { Formulation can either be a solution of drug or a } \\
\text { carrier based system }\end{array}$ & $\begin{array}{l}\text { Ease of application; similar to eye drops } \\
\text { Opcurs; leading to slow release of drug from } \\
\text { polymeric matrix. }\end{array}$ \\
\hline $\begin{array}{l}\text { Carrier based } \\
\text { systems }\end{array}$ & $\begin{array}{l}\text { Nanoparticles: colloidal particles composed of } \\
\text { either polymers or surfactant molecules. Drug is } \\
\text { entrapped within the polymer matrix. } \\
\text { Lipid based systems: vesicular systems, mimic } \\
\text { natural cell membrane thus highly compatible }\end{array}$ & $\begin{array}{l}\text { Sustained drug delivery due to penetration of } \\
\text { ocular barriers } \\
\text { Surface modification by use of mucoadhesive } \\
\text { leads to enhanced efficacy } \\
\text { Non-toxic, biocompatible, non-immunogenic } \\
\text { and biodegradable }\end{array}$ \\
\hline Implants ${ }^{24}$ & $\begin{array}{l}\text { Biodegradable or non-biodegradable implants } \\
\text { placed into vitreous cavity }\end{array}$ & $\begin{array}{l}\text { Though the process is invasive, but sustained } \\
\text { drug delivery can be extended up to few years } \\
\text { thus ensuring good therapeutic outcome }\end{array}$ \\
\hline
\end{tabular}

\section{NIOSOMES IN OCULAR DRUG DELIVERY}

These are bilayered, lamellar structures primarily composed of non ionic surfactants and a rigidizing agent which are hydrated by different methods in order to form a vesicle. They are either unilamellar or multilamellar enclosing an aqueous compartment. Being amphiphilic in nature, the non ionic surfactants are known to possess the ability to self assemble. Critical parameters in niosome preparation govern the formation of vesicular structures instead of micelles ${ }^{4,26-27}$. The surfactants being non-ionic in nature do not cause any irritation to the ocular tissue and their ability to act as penetration enhancers can also be exploited. 


\section{Advantages of Niosomes Pertaining to Ocular Delivery:}

i. Size: It usually lies in $\mathrm{nm}$ range, easily tolerated by eyes as opposed to microparticulate systems ${ }^{28}$.

ii. Stability: Non ionic surfactants are stable, not prone to oxidation etc., leakage of drugs as seen in liposomes is circumvented ${ }^{4,26}$.

iii. Ease of handling: The components do not have any special handling problems ${ }^{4,28}$.

iv. Cost effectiveness: It is one of the less expensive carrier systems ${ }^{29}$.

v. Storage: The storage conditions are more flexible with niosomes because of use of non ionic surfactants $^{27,28,30}$.

vi. Biodegradability, biocompatibility and relative non-toxicity is observed ${ }^{4,29}$.

vii. Versatility: It is successful in entrapping water soluble and water insoluble drugs ${ }^{28,30}$.

viii. Osmotically active and stable ${ }^{28,30}$.

ix. Prevent ocular metabolism of drugs by lachrymal fluid $^{27,30}$.

\section{Composition of Niosomes}

These vesicular systems are essentially alternatives to liposomes. The non ionic surfactants possess versatility and ease of handling thus are easy to fabricate. Other than surfactants, membrane additives are also used in preparation, to enhance the properties of these systems and ensure good outcomes. The various materials used are described hereunder:

Non-ionic Surfactants: They usually contain a hydrophobic tail and a hydrophilic head group and have ability to self assemble. HLB values of these surfactants play an important role in their ability to form vesicles. Various classes of non ionic surfactants that are used to form niosomes are given as follows ${ }^{26-27,30-31}$ :

i. Ether linked surfactants: these include alkyl ethers and alkyl glyceryl ethers which have high stability. Some of the examples are: Brij 30, Brij 58, Brij 72.

ii. Sorbitan fatty acid esters: the esters which are formed upon interaction of plain sorbitan with fatty acids are called Spans. There are different varieties on basis of chain length of fatty acids; such as Span 20, Span 40, Span 60 and Span 80. They are widely used for preparation of niosomes.

iii. Polyoxyethylene fatty acid esters: these include water soluble surfactants, and are liquid in nature formed by interaction between PEGy-lated sorbitan esterified with fatty acids. The examples include: Tween 20, Tween 80 and Tween 28 etc.

iv. Others: few non ionic surfactants such as Bola surfactant, Gemini surfactant and Solulan C24 have also been evaluated for preparation of niosomes.

Membrane Stabilizing Agent: Cholesterol is incorporated with non ionic surfactants in order to form vesicles. Addition of cholesterol helps in stabilizing the bilayer that is formed prevents the phase transition changes of surfactants thus forming niosomes which are less leaky in nature ${ }^{29-30}$.
Charge Inducing Agents: these may be incorporated in the formulation in order to prevent aggregation of the formed vesicles thus diminish any instability that may so exist. Examples include Dicetylphosphate, Stearylamine, Cetylpyridinum chloride, etc., ${ }^{27,29}$.

\section{FABRICATION OF OCULAR ANTI- HYPERTENSIVE AGENTS INTO NIOSOMES}

A lot of research has been conducted to develop novel niosomal drug delivery systems for management of glaucoma. Different classes of drugs have been formulated as niosomes and the results have shown effective drug delivery, prolonged duration of action and reduced systemic side effects. Few of the examples are listed below:

- Acetazolamide: It is prescribed orally for treatment of glaucoma and accompanied with a plethora of systemic side effects. The limited solubility and permeability encountered with the drug further raises difficulty in developing a topical preparation $^{32}$. Niosomes have been developed for this drug ${ }^{33-35}$. In a research, methods of preparation and charge inducers were varied and bioadhesives were also used to enhance efficacy. It was observed that reverse phase evaporation yielded niosomes with highest entrapment efficiency and those with bioadhesive coating were known to prolong the IOP lowering effect of the formulation ${ }^{33}$. Use of PEG 400 in preparation of niosomes was investigated for its action on solubility of drug and penetration enhancement. Ocular bioavailability increased and IOP lowering effect was rapid ${ }^{36}$.

- Timolol maleate: Use of mucoadhesive agents for prolonging the residence time of the niosomal formulations has been well documented. In one such niosomal formulation of Timolol maleate, various agents such as Chitosan, Carbopol 934P and Carbopol 974P were used to coat the surface of niosome. Pharmacodynamic effect was evaluated, chitosan coated timolol maleate significantly reduced IOP for a prolonged duration of $8 \mathrm{~h}$ and also a reduction in overall side effects was observed $^{37}$. Ocular absorption profile was evaluated and results indicated that peak concentration of drug in aqueous humor is 1.7 times more than that seen with pure drug solution leading to enhanced efficacy $^{38}$.

- Brimonidine tartrate: Comparative study by preparing liposomes and niosomes was conducted, results predicted better drug release profile, stability profile and increased in-vivo IOP lowering effect of niosomes [39]. Coating of niosomes of the drug by Carbopol 940 was done, duration of action was found to have been extended up to $8 \mathrm{~h}$ where substantial decrease in IOP was observed and also no evidence of potential irritancy to eyes was observed $^{40}$.

- Ocular Gel: In-situ gelling systems were also developed using niosomes of brimonidine tartrate prepared by thin film hydration. Polymers used for gelling were carbopol 940 and HPMC K15M (in a definite ratio) in acetate buffer. The niosomes upon 
instillation into eye formed a gel like matrix and gel exhibited pseudoplastic rheology. Gel systemshowed extended action up to $8 \mathrm{~h}^{41}$. Niosomal hydrogel of atenolol was formulated using various polymers (chitosan, carbopol 934P, sodium alginate). Atenolol/Carbopol hydrogel showed best result with 4.33 fold increase in AUC after $8 \mathrm{~h}$ of administration ${ }^{42}$.

- Combination Dosage Form: Niosomes were prepared by thin film hydration technique using by using brimonidine tartrate and timolol maleate. Additive effect was observed in the IOP lowering activity of the combination. The in-vivo IOP lowering activity was also compared with Combigen (marketed formulation) and it was observed that there was a rise in IOP $4 \mathrm{~h}$ after administration of Combigen whereas niosomal preparations showed as much as $12 \mathrm{mmHg}$ reduction in IOP after $6 \mathrm{~h}$ of administration ${ }^{43}$.

\section{CONCLUSION}

Glaucoma is on the rise and being a life-long condition, it demands daily use of medications in order to stall the nerve damage that occurs. Dosage forms which can prolong duration of action of drugs must be developed. In such situations niosomes present as a competent solution that not only have enhanced efficacy and stability but also minimum side effects. They exhibit increased ocular bioavailability of both hydrophilic and lipophilic drugs. Biocompatibility and biodegradability of these systems further outline their utility in drug delivery. Thus niosomes can be further probed in this regard and an effective drug delivery system be designed.

\section{REFERENCES}

1. Imam S, Bansal A, Bushetti SS, Singh A, Chopra H, Novel ocular dosage form in treatment of glaucoma, The Pharma Research, Sudarshan Publication, 2009, 1, 72-81.

2. Saxena R, Singh D, Vashisht P, Glaucoma: An emerging peril. Indian J Community Med, 2013, 38(3), 135-137.

3. Kaur I P, Garg A, Singla A K, Aggarwal D. Vesicular systems in ocular drug delivery: an overview, I J Pharm, 2004, 209, 1-14.

4. Sahoo R K, Biswas N, Guha A, Sahoo N and Kuotso K, Nonionic surfactant vesicles in ocular delivery: Innovative approaches and perspectives, BioMed Res. Int., Hindawi Publishing Corporation, Vol. 2014, 1-12.

5. Lohumi A, Rawat S, Sarkar S, Sipai AB, Yadav M.V, A novel drug delivery system: niosomes review, Journal of drug delivery and therapeutics, 2012; 2(5):129-135

6. Tham Y C, Li X, Wong T Y, Quigley A H, Aung T, Cheng C Y, Global prevalence of glaucoma and projections of glaucoma burden through $2040 \mathrm{~A}$ systematic review and meta-analysis, Ophthalmology, 2014, 121(11), 2081-2090.

7. Giangiacomo A, Coleman AL. The epidemiology of glaucoma, Glaucoma, Springer Berlin Heidelberg, 2009, Pg 13-21.

8. Quigley H A, Broman A T, The number of people with glaucoma worldwide in 2010 and $2020, \mathrm{Br} \mathrm{J}$ of Ophthalmol., 2006, 90, 262-267.

9. Dandona L, Dandona R, Srinivas M, Mandal P, John RK, McCarty CA, Rao GN, Open angle glaucoma in an urban population in southern India: the Andhra Pradesh eye disease study, Ophthalmology, 2000, 107(9), 1702-9.

10. Ramakrishnan R, Nirmalan PK, Krishnadas R, Thulasiraj RD, Tielsch JM, Katz J, Friedman DS, Robin AL,
Glaucoma in a rural population of southern India: the Aravind comprehensive eye survey, Ophthalmology, 2003, 110(8), 1484-90.

11. Vijaya L, George R, Paul PG, Baskaran M, Arvind H, Raju P, Ramesh SV, Kumaramanickavel G, McCarty C, Prevalence of open angle glaucoma in a rural south Indian population, Invest Ophthalmol Vis Sci., 2005, 46(12), 4461-7.

12. Moore DB, Glaucoma in the developing world, Available from: www.eyewiki.aao.org.

13. Patient Guide, The Glaucoma Foundation, Available from: https://www.glaucomafoundation.org/docs/PatientGuide.pd $\mathrm{f}$

14. Medication Guide, Glaucoma Research Foundation, Available from: www.glaucoma.org.

15. Quigley AH, Number of People with Glaucoma Worldwide, Br J Ophthalmol., 1996, 80, 389-393.

16. Leske MC, Connell AM, Schachat AP, Hyman L, The Barbados eye study, Prevalence of open angle glaucoma, Arch Ophthalmol., 1994, 112(6), 821-9.

17. Leske MC, Connell AM, Wu SY, Nemesure B, Li $\mathrm{X}$, Schachat A, Hennis A, Incidence of open-angle glaucoma: the Barbados eye studies, The Barbados eye studies group, Arch Ophthalmol., 2001, 119(1), 89-95.

18. Cho HK, Kee C, Population-based glaucoma prevalence studies in Asians, Surv Ophthalmol., 2014, 59(4), 434-47.

19. Traverso CE, Walt JG, Kelly SP, Hommer AH, Bron AM, Denis $P$ et al., Direct costs of glaucoma and severity of the disease: a multinational long term study of resource utilisation in Europe, Br J Ophthalmol., 2005, 89, 12451249.

20. Thyleforl B, Negrel A.D, The global impact of glaucoma, Bulletin of the World Health Organization, 1994, 72(3), 323-326.

21. Varma R, Lee PP, Goldberg I, Kotak S, An Assessment of the Health and Economic Burdens of Glaucoma, Am J Ophthalmol., 2011, 152(4), 515-522.

22. Covin YN, Laroche D, The societal costs of blindness from uncontrolled glaucoma, Glaucoma Today, 2014, Jul-Aug, 28-29.

23. Kumari A, Sharma PK, Garg VK, Garg G, Ocular insertsAdvancement in therapy of eye diseases, J Adv Pharm Technol Res., 2010, 1(3), 291-296.

24. Patel A, Cholkar K, Agrahari V, Mitra AK, Ocular drug delivery systems: An overview, World J Pharmacol., 2013, 2(2), 47-64

25. Xu Q, Kambhampati SP, Kannan RM, Nanotechnology approaches for ocular drug delivery, Middle East Afr J Ophthalmol., 2013, 20(1), 26-37.

26. Kumar GP, Rajeshwarrao P, Nonionic surfactant vesicular systems for effective drug delivery-an overview, Acta Pharmaceutica Sinica B, 2011, 1(4), 208-219.

27. Sankhyan A, Pawar $P$, Recent trends in niosome as vesicular drug delivery system, J. Appl. Pharm. Sci., 2012, 2(06), 20-32.

28. Mujoriya RZ, Dhamande K, Dr. Bodla R B, Niosomal drug delivery system- A Review, Int. J. Appl. Pharm., 2011, 3(3), 7-10.

29. Dahiya N K, Rao R, Nanda S, Preparation and characterization techniques in niosomal vesicular systemsA Review, J. Pharm. Biomed. Sci., 2011, 5(20), 1-8.

30. Singh S, Niosomes: A role in targeted drug delivery systems, Int. J. Pharm. Sci. Res., 2013, 4(2), 550-557.

31. Arora V, Rastogi S, Siddiqui AW, Gupta M, Bhalla V, Pharmaceutical applications of nano-niosomes in drug, vaccine and gene delivery, Int. J. Pharm. Sci. Nanotechnol., 2014, 7(4), 2603-2611.

32. Kaur I P, Smitha R, Aggarwal D, Kapil M, Acetazolamide: future perspective in topical glaucoma therapeutics, Int. J. Pharm., 2002, 248, 1-14.

33. Aggarwal D, Garg A, Kaur I P, Development of a topical niosomal preparation of acetazolamide: preparation and evaluation, J Pharm. Pharmcol., 2004, 56, 1509-1517. 
34. Kaur I P, Mitra A K, Aggarwal D, Development of a vesicular system for effective ocular delivery of acetazolamide A comprehensive approach and successful venture, J. Drug Del. Sci. Tech., 2007, 17(1), 33-41.

35. Guinedi A S, Mortada N D, Mansour S, Hathout R M, Preparation and evaluation of reverse-phase evaporation and multilamellar niosomes as ophthalmic carriers of acetazolamide, Int. J Pharm., 2005, 306, 71-82.

36. El-Menshawe $\mathrm{S}$ F, A novel approach to topical acetazolamide/PEG 400 ocular niosomes, J. Drug Del. Sci. Tech., 2012, 22(4), 295-299.

37. Aggarwal D, Kaur I P, Improved pharmacodynamics of timolol maleate from a mucoadhesive niosomal ophthalmic drug delivery system, Int. J. Pharm., 2005, 290, 155-159.

38. Kaur I P, Aggarwal D, Singh H, Kakkar S, Improved ocular absorption kinetics of timolol maletae loaded into a bioadhesive niosomal delivery system, Graefe's Arch. Clin. Exp. Ophthalmol., 2010, 248, 1467-1472.

39. Prabhu P, Nitish $\mathrm{R}$ K, Koland M, Harish NM, Vijayanarayan K, Dhondge G, Charyulu N, Preparation and evaluation of nano-vesicles of brimonidine tartrate as an ocular drug delivery system, J Young Pharm., 2010, 2(4), 356-361.

40. Maiti S, Paul S, Mondol R, Ray S, Sa B, Nanovesicular formulation of brimonidine tartrate for the management of glaucoma: In vitro and in vivo evaluation, AAPS PharmSciTech., 2011, 12, 755-763.

41. Satyavathi V, Hasansathali, Ilavarasan R, Sangeetha T, Formulation and evaluation of niosomal in situ gel ocular delivery system of brimonidine tartrate, International Journal of Life Science and Pharma Research, 2012, 2(1), 82-95.

42. Hashim AII, El-dahan MS, Yusif RM, Abd-ElGawad AH, Arima H, Potential use of niosomal hydrogel as an ocular delivery system for atenolol, Biol. Pharm. Bull., 2014, 37(4), 541-551.

43. Dubey A, Prabhu P, Development and investigation of niosomes of brimonidine tartrate and timolol maleate for the treatment of glaucoma, Int. J. PharmTech Res., 2014, $6(3), 942-950$. 